Motivators and Inhibitors to Reserving Hotel Accommodations via Smartphones

Sangwon Park, PhD

Senior Lecturer

Hospitality and Food Management

School of Hospitality and Tourism Management

University of Surrey

53MS02

Guildford, Surrey, GU2 7XH United Kingdom

e-mail: sangwon.park@surrey.ac.uk

\title{
Yiqun Huang
}

MSc student

International Hotel Management

School of Hospitality and Tourism Management

University of Surrey

53MS02

Guildford, Surrey, GU2 7XH United Kingdom e-mail: yh00060@surrey.ac.uk 


\title{
Title: Motivators and Inhibitors in Booking a Hotel via Smartphones
}

\begin{abstract}
Purpose - The purpose of this research is to identify motivators (i.e. self-efficacy, perceived behavioural control and perceived benefits) and inhibitors (i.e. perceived cost and anxiety) that affect behavioural intentions to book hotel rooms using smartphones.
\end{abstract}

Design/methodology/approach - Utilising survey data collected from online consumers who have booked hotels in London, two stages of structural equation modelling were applied to estimate the proposed model.

Findings - The results of this research indicate that perceived behavioural control appears to be the core motivator for the use of smartphones to book a hotel with perceived benefits, whereas anxiety plays a negative role in leading to mobile booking behaviours. It is also identified that self-efficacy indirectly influences intentions to reserve hotel accommodation.

Practical implications - This study suggests that hospitality marketers should (1) simplify the mobile purchasing process to enhance self-confidence in controlling the system during transactions; (2) educate current and potential online consumers to become aware of the competitive benefits of using smartphones; and (3) create alliances with credit card companies in order to relieve anxiety when users are asked to provide personal or banking information.

Originality/value - In light of the substantial literature regarding the adoption of technology in terms of user experience (i.e. TAM), this study integrates two theoretical foundations of understanding consumer behaviours (i.e. a concept of consumer values and theory of planned 
behaviour) to assess motivators and inhibitors in behaviours related to booking hotel accommodation via smartphones.

Keywords: smartphones, consumer values, theory of planned behaviours, online hotel booking behaviour

Paper type: Research paper 


\section{Introduction}

Smartphones and tablets are revolutionising consumers' planning, research and execution in the decision-making process. Expedia Media Solutions (2015a) reported that about $69 \%$ of UK travellers and $58 \%$ of American travellers engage with digital travel content using their smartphones. While the use of PCs has decreased by $9 \%$, the number of online travellers who use smartphones to plan their travel journey has increased by $39 \%$ compared to the previous year (Expedia Media Solutions, 2015b). This remarkable phenomenon in the utilisation of smartphones implies a potential capacity for advanced information and communication technology (ICT) in the hospitality and tourism industry because the ubiquity of mobile information services enables people to gain benefit from spatial, temporal and contextual mobility (Rasinger et al., 2009).

Recently, several scholars in hospitality and tourism have endeavoured to understand the usage of smartphones in relation to information search behaviours and the travel planning process, and ultimately for identifying the structure of enhanced travel experiences (Park and Wang, 2013; Tussyadiah and Zach, 2012; Wang et al., 2012, 2014). This suggests that previous studies investigating advanced information technology (i.e. smartphones) have focused primarily on the travel planning process in general and the aspect of information search behaviours in particular. Importantly, however, there is little research assessing the stage of a purchase decision (i.e. transactional phase) along with the advancement of information technology (Bouwman et al., 2007; Wu et al., 2013).

Hotels and other forms of accommodation comprise a type of hospitality product that most online travellers are likely to access on smartphones; however, it seems that these products are less likely to be purchased via mobile phones. According to the HeBS Digital hotel client portfolio (2012), about $14.0 \%$ of visits to hotel websites occur via mobile phones, while just $2.6 \%$ of them completed bookings on the device, generating $1.1 \%$ of total revenues 
for hotels. These statistics suggest an important research issue: to identify those factors that drive or inhibit consumers' hotel booking decisions via smartphones.

There are a number of extant studies that investigate the adoption of technology in the hospitality area. Indeed, the dominant paradigm used to assess the adoption of mobile information services is the Technology Adoption Model (TAM), originally developed to explain individuals' adoption of technology in an organisational setting (Kim et al., 2008; Tsai et al., 2011). The theory argues that the adoption of information technology (IT) services is largely determined by two factors: perceived usefulness and ease of use, which leads to limited explanatory power of the behaviour. Additionally, it focuses on the drivers leading to the behavioural intentions in terms of the technological aspect. However, from the consumer behaviour perspective, adopters of new ICTs are individuals who play the dual roles of technology user and service consumer, and thus tend to evaluate the services in regard to perceived values. Thus, the authors of this paper argue that the concept of perceived value comprising perceived benefits and sacrifice, which includes perceived cost and risk (anxiety), is important to consider as one of the underlying concepts in this study (Kim et al., 2007). Furthermore, the theory of planned behaviour (TPB) is a well-developed model that has been shown to predict behaviours across a variety of settings. In particular, this theory suggests the influential roles of perceived behaviour control (Pavlou and Fygenson, 2006) and self-efficacy (Iconaru, 2013) in understanding online consumer behaviours.

This research contributes to understanding factors that positively and negatively influence purchasing behaviours using smartphones. The integration of the two important theories (consumer value and TPB) relevant to consumer behaviours provides a comprehensive insight into purchasing behaviours (transactional stage) rather than focusing on the information search stage. Thus, this paper aims to identify motivators (i.e. self-efficacy, perceived behavioural 
control and perceived benefits) and inhibitors (i.e. perceived cost and anxiety) that affect behavioural intentions to book hotel rooms using smartphones.

\section{Related work}

Due to the nature of hospitality products (inherently experiential, intangible and heterogeneous), assessing the quality of products before purchasing is difficult for consumers. Hence, consumers seek recent and relevant information to reduce the level of information asymmetry, i.e. the difference of information between sellers and buyers (Pavlou et al., 2007). Highly innovative location-based services allow online consumers to obtain personalised and "last minute" information based upon their current location (Krum, 2010), which means that travel behaviours are adaptable to the specific context with which they are confronted (Kramer et al., 2007).

In recognising the important role of smartphones, several researchers have attempted to identify factors that influence the adoption of smartphones for travel purposes. Oh et al. (2009) applied expectance theory, comprising performance and effort expectancies, to understand behavioural intention to use mobile devices for future travel. Kim et al. (2008) applied TAM theory with two external variables, technology and trip experiences, to identify the determinants leading to tourists' acceptance of mobile devices. Recently, a series of studies conducted by Morosan (2014) proposed an extensive TAM in purchasing ancillary airline services, accepting biometric systems for security in air travel, and using mobile devices in private clubs.

While TAM has been extensively used and makes significant contributions to understanding the adoption of IT, it has limitations in accounting for user behaviours. First, the theory suggests two types of belief (i.e. perceived usefulness and ease of use) to explain the likelihood of using a technology, which has restrictions in terms of the predictive power of 
those two factors. The parsimony of the TAM leads to the unreasonable argument that a simple model can explain a behaviour fully across a wide range of technologies and decision situations (Bagozi, 2007). Furthermore, the TAM model has been developed in the organisational context where people use free-of-charge technology daily for work purposes. In contrast, individual users adopt new technology for their personal purposes, which requires usage fees to be paid for voluntary adoption. This implies that there is a need for a systematic investigation and theorising of the relevant factors that would be applicable to the context of consumer technology use.

In recognising the limitation of the TAM, several scholars in hospitality and tourism have applied various approaches to explain the behavioural usage of advanced ICT: for example, the unified theory of acceptance and use of technology for purchasing flight tickets (Escobar-Rodrıguez and Carvajal-Trujillo, 2014), hedonic consumption experiences in using virtual 3D systems (Huang et al., 2013), and a complex model combining TPB, TAM and innovation diffusion theory (IDT) for online travel shopping (Amaro and Duarte, 2015). However, these studies mainly explore the general online context rather than highlighting the mobile technology. Although Okazaki and Hirose (2009) examine the use of mobile Internet in the hospitality and tourism industry, the research highlighted the relationship between satisfaction and attitudes towards mobile Internet.

From the consumer behaviour perspective, perceived value is regarded as an important determinant of behavioural intention. In other words, consumers are likely to choose a behaviour by working out a way to maximise the value comprised of the trade-off between total benefits and sacrifice when deciding to use a new technology (Kim et al., 2007). Wang and Wang (2013) examined the perceived values in accounting for behavioural intentions to adopt mobile services for hotel reservations. The results of the study concluded that perceived benefits and sacrifices consisting of perceived cost and anxiety (or risk) form the perceived 
value inducing adoption behaviour. In addition, this study takes into account TPB, which is one of the primary theories of human behaviour and emphasises perceived behavioural control and self-efficacy. In other words, it is suggested that perceived ability to control a new technology (i.e. advanced mobile phones) is vital in leading to adoption behaviour. The following section discusses the relationships between the theoretical factors examined in this research (see Figure 1).

\section{Hypothesis development}

\section{Perceived behavioural control}

Ajzen (1991) developed the Theory of Planned Behaviour (TPB) based on the Theory of Reasoned Action (TRA) by adding perceived behavioural control as a crucial factor. In the view of Ajzen (1991), perceived behavioural control, defined as "individual perception of the ease or difficulty of performing the behaviour of interest" (Ajzen, 1991, p.183), is an extended determinant that affects the intentions that enable the reasons for individual actions to be understood. Accordingly, in this study, perceived behavioural control refers to consumers' perceptions of the ease or difficulty of obtaining information about a hotel and booking the hotel room via a smartphone application. Indeed, when individuals perceive technology as being easily manipulated and within their control, their confidence in using a new technology and the outcome derived increases and leads to the formation of a favourable attitude towards purchasing products via a certain technological device (Al-Swidi et al., 2012; Hansen, 2008). Thus, the current study argues that for those travellers with sufficient confidence to use mobile devices (i.e. a high level of perceived behavioural control), attitudes towards purchasing products or services via a smartphone become favourable, which increases the likelihood of making hotel reservations (Maity, 2010). Thus, this study proposes the following hypothesis: 
H1: Perceived behaviour control has a positive effect on the intention to reserve hotel accommodation using a smartphone.

\section{Perceived benefits}

The development of informational technology enables consumers to evaluate and use relatively convenient, effective and inexpensive channels to purchase travel products (Buhalis and Law, 2008), which brings about perceived benefit to technology users (Kim et al., 2008). Smartphones help consumers to obtain ubiquitous, convenient, personalised and location-based benefits when searching for information to decide on a purchase (Akturan and Tezcan, 2012). More specifically, the mobile reservation channel allows travellers to receive location-based recommendations, corresponding to a certain moment when people seek to accomplish specific tasks by using smartphones.

Liebermann and Stashevsky (2009) reviewed a substantial number of studies that discuss the determinants of online shopping, and suggested that consumers who recognise the benefits of using information technology, including in-depth information, social interaction, convenience, selection and availability, tend to increase their likelihood of purchasing online (Wolfinbarger and Gilly, 2001). In other words, consumers assess certain benefits from the solution to a need that a product offers and consider the comprehensive attributes that deliver benefits (Kotler and Armstrong, 2003). Thus, it can be argued that when travellers use mobile phones to reserve hotel accommodation, they can reduce the time and costs required for searching, and encounter a wider range of informational alternatives for products and services, thereby leading to an increased likelihood of reserving hotel rooms via their smartphone. The following hypothesis is proposed: 
H2: Perceived benefit has a positive effect on the intention to reserve hotel accommodation using a smartphone.

\section{Perceived costs}

Previous studies of consumer behaviour have identified a trade-off between perceived benefits and costs during the decision-making process for a purchase. The perceived costs consist of monetary and non-monetary aspects (Hauser and Wernerfelt, 1990); for example, effort costs, difficulty of use and risk to privacy in using ICT for booking a hotel (Parra-López et al., 2011). Effort costs refer to money and time spent adapting ICT for searches, communication and transactional activities (Patterson and Smith, 2001). The difficulty of use indicates the extent to which the use of a technological device is difficult for people as they attempt to obtain customised information, and produces unsatisfactory search results. A number of MIS researchers have broadly suggested the importance of ease of use as a vital factor that leads to adopting behaviour for employing new ICT (Gefen et al., 2003). The third element reflects anxiety and/or perceived risk, which is discussed in some depth as an important factor in itself. Thus, the next section focuses on the notion of anxiety in more detail.

In terms of mobile phones, while sifting and simplifying information and content on smartphones would fit the "relatively" small screens of the devices, there is a potential limitation in that this may not present sufficient information to meet the user's informationseeking needs (Chan et al., 2002). In other words, when adopting a new type of ICT, consumers incur relatively higher levels of cognitive costs in using it and accomplishing the specific tasks with the technology (Maity, 2010; Swartz, 2001). Therefore, the following hypothesis is proposed: 
H3: Perceived cost has a negative effect on the intention to reserve hotel accommodation using a smartphone.

\section{Anxiety}

Anxiety refers to transitory unpleasant and negative emotions in cognitive states evoked in actual or imaginary interactions in online purchasing experiences (Thatcher and Perrewe, 2002). These negative emotions include feeling fearful, worried, apprehensive and uneasy. Adopting a new technology, imagination or physical experiences may engender uncertainty over outcomes, which leads to negative emotions. More specifically, when online travellers receive requests to provide their personal information, such as demographic and banking details in the payment process, anxiety may arise from losing control if transactional errors occur (Kuisma et al., 2007). With regard to intangibility in the m-commerce (mobile commerce) environment, where mobile devices are used to communicate and carry out transactions through public and private networks (Balasubramanian et al., 2002), consumers may also experience perceived uncertainty over unexpected product performance.

Several studies have examined the direct and indirect negative effects of anxiety on the use of information technology (Beaudry and Pinsonneault, 2010; Lu and Su, 2009). Beaudry and Pinsonneault (2010) indicated that individuals who have a high level of anxiety behave more rigidly and cautiously when using technology than those who are less likely to be anxious. In the mobile purchasing context, Yang and Forney (2013) showed the negative relationship between anxiety and mobile shopping behaviour due to a lack of confidence derived from a high level of anxiety. Therefore, the following proposed hypothesis tests the effect of anxiety:

H4: Anxiety has a negative effect on the intention to reserve hotel accommodation using a smartphone. 


\section{Self-efficacy}

Based on the social cognitive theory (Bandura, 1994), self-efficacy refers to the level of confidence individuals have regarding the successful completion of a task within their capacity to do so as a proximal determinant of one's behaviour. Accordingly, this research defines selfefficacy in the context of mobile technology as confidence in one's ability to conduct an online hotel booking and confidence in accomplishing tasks based upon perceived ability to use smartphones (Compeau and Higgins, 1995).

Several previous studies have discussed the effect of self-efficacy on technological experiences (Kim et al., 2011). Pavlou and Fygenson (2006) demonstrated that judgment of consumers' ability to gain information about a product online has a positive and indirect influence on consumers' actual purchase behaviour. A recent study by Yang (2012) came to the same conclusion in the mobile context. Indeed, high self-efficacy increases one's enthusiasm and applies cognitive resources so as to increase the amount of endeavour, effort and self-regulation. When consumers become confident in using mobile phones, they are likely to explore more functions and features that enhance outcomes from mobile shopping, and in turn become more comfortable employing purchasing behaviour via the mobile channel (Iconaru, 2013).

In addition, studies suggest that self-efficacy is an influential factor in alleviating anxiety (Bandura, 1994). Consumers with a high level of self-efficacy regard the adoption of purchasing via advanced IT as a challenge; in contrast, those with a low level of self-efficacy consider technology to be a threat that causes a high level of cognitive stress and negative feelings, leading to unwillingness to use information technology. In the same vein, Fagan, Neill and Wooldridge (2003) demonstrated that individual self-efficacy negatively relates to anxiety over using new technology. Hence, the following hypotheses can be proposed: 
H5a: Self-efficacy has a positive effect on perceived behavioural control.

$H 5 b$ : Self-efficacy has a negative effect on anxiety.

[Insert Figure 1 here]

\section{Research method}

\section{Data collection}

An online survey, conducted from June to August 2013, collected relevant data through the social media website TripAdvisor, which is one of the most popular social community websites for sharing travel experiences and is ranked among the top five apps in the Apple store in the travel category. Specifically, the randomly contacted participants were those who posted comments regarding hotel experiences in London, UK. The sample frame includes online travellers who have stayed in hotels in London. London is one of the most popular travel destinations. It was visited by 160.2 million travellers in 2013 and numbers are expected to rise to 179 million by 2018 (Mintel, 2014a). According to a report by Mintel (2014b), London supplies $22 \%$ of the room provision in the entire UK. Of those who stayed in London hotels, $91 \%$ used information technology (i.e. mobiles) when booking hotels. These statistics indicate that London is a relevant strength in the specific setting of this research. More specifically, given that the total number of London hotels listed on TripAdvisor is approximately 1,000, the researchers randomly selected 100 hotels, reflecting $10 \%$ of the total number of hotels. Then, every tenth user who actually posted reviews on each hotel was contacted to ask about his or her intention to participate in the survey with a cover letter by using a TripAdvisor messaging tool. The logic is that those people who have left online comments regarding their hotel experiences are accustomed to using advanced technology for other activities in their everyday 
lives. Thus, this way of contacting the study sample is appropriate for addressing the purposes of this research. More specifically, the initial approach to potential participants included detailed information about the purposes of the research in requesting participation through the provided survey. Upon receipt of agreement from the online travellers, they received a link to access the online questionnaire along with an explanation of the mechanics for responding. As a result, the total number of valid responses considered for data analysis was 295 , excluding 10 respondents who did not complete the entire survey (response rate: about $11 \%$ ).

Further, in order to identify relevant samples, the process of data collection included filter questions: (1) "Do you own a smartphone or mobile phone that can access the Internet?" and (2) "Did you use a smartphone or mobile phone to search for information about the hotel(s) in which you stayed in London, UK?" These questions allowed the researcher to ascertain that respondents not only have access to a relevant technological device related to the research's context (i.e. smartphones), but also have experience in using mobile phones to search for accommodation.

\section{Measurement development}

The survey consists of three sections. The first section inquires of participants' travel and smartphone experiences. Specifically, the questions asked for types and number of travel companions, length of stays in a hotel, and travel budget per days. The second section includes multiple items to measure six theoretical variables with a five-point Likert scale, including perceived behavioural control, perceived benefits, perceived costs, anxiety, self-efficacy, and behavioural purchasing intention, to address the purpose of this research. The scales of the variables are adaptations from previous studies which exhibited relatively high levels of reliability and validity. 
The items of perceived behavioural control include four questions derived from Taylor and Todd (1995), and Yang (2012). Five items on perceived benefits and six items of perceived costs are adaptations similar to those of Park and Kim (2006) and Parra-López et al. (2011). The current research used three items to measure anxiety (Compeau et al., 1999; $\mathrm{Lu}$ and $\mathrm{Su}$, 2009; Thatcher and Perrewe, 2002) and three items, adapted from Compeau and Higgins (1995) and Kim et al., (2011), to measure self-efficacy. For behavioural intentions, three items relied on the suggestions of Lee et al., (2002) and Yang (2012). The final section seeks demographic information: gender, age, marital status, and level of education.

\section{Data analysis}

Descriptive analysis determined the characteristics of the sample and identified the distributions of the data relevant to the variables in the theoretical model. Then, Confirmatory Factor Analyses (CFA) estimated the measurement model to check reliability and validity of the constructs using M-Plus software. A number of methods for the model's fit considered factor loadings (or indicator reliability) (above 0.70), composite reliability of the latent constructs (above 0.70). chi-square $\left(\chi^{2}\right)$, Comparative Fit Index (CFI) (above 0.90), TuckerLewis Index (TLI) (above .90), root mean square error of approximation (RMSEA) (less than 0.05) and root mean square residual (RMSR) (less than 0.05) (Nunnally and Bernstein, 1994). Furthermore, guiding post-hoc analysis of the model used statistical output but in accordance with underlying theory to ensure maintaining the psychometric properties of each construct (Kline, 2011). Next, the structural model in a part of structural equation modelling (SEM) analysis was estimated by considering the same goodness-of-fit indexes such as CFI, TLI, RMSEA, and RMSR included are concerned with $\mathrm{R}^{2}$. The indication from the $\mathrm{R}^{2}$ values of $0.75,0.50$, or 0.25 is that the endogenous constructs are high, moderate, and weak, respectively. 


\section{Results}

Profiles of respondents

Female respondents $(54.9 \%)$ are slightly more than males $(45.1 \%)$. Online travellers in this research appear relatively high level of education: about $90 \%$ of respondents completed college or above with 31.68 of the average age. With regard to travel behaviours visiting London, $41 \%$ of respondents have travelled with spouse/partners, followed by with friends (31.9\%). Asking their behaviours about hotel stay, $57.9 \%$ of travellers have stayed in the hotel between 1 and 3 days while visiting the UK.

\section{Measurement Model}

Confirmatory factor analysis was used to test the validity and reliability of the theoretical constructs by the latent variable approach using M-Plus software. Checking the factor loadings, two items below cut-off values are decided to be eliminated: one of perceived behavioural control (PBC_2: “The given resources, opportunities and knowledge take me to use mobile booking" $=0.24)$ which is consistent with the result of exploratory factor analysis, and an item of perceived costs (PC_2: "The monetary costs of the equipment and services for using mobile hotel booking are too high" $=0.50$ ). After the modification, all the factor loadings are over 0.68 which means that interrelations are significantly high in magnitude ( $\mathrm{p}<.001)$ (Kline, 2011). The results of composite reliability also show reasonable values, including perceived behavioural control (0.93), perceived benefit (0.92), perceived cost (0.92), anxiety (0.92), selfefficacy (0.96), and behavioural intention (0.97) (see Table 1).

[Insert Table 1 here] 
The square root of Average Variance Extracted (AVE) was calculated to test the convergent validity for six latent variables and then, the values are compared with other constructs to assess discriminant validity. The results of the analysis show that the AVEs (the mean-squared loading for each construct) of each construct are larger than the crosscorrelations of other constructs, which suggests the each reflective construct is distinct from other constructs in the measurement model: the confirmation of discriminant validity. The squared AVE is also over .82, implying that the latent variables explain its indicators more than error variance: the confirmation of convergent validity (see Table 2). Furthermore, there is no correlation value over 90 which limits the collinearity between constructs.

\section{[Insert Table 2 here]}

The various goodness-of-fit indexes for confirmatory factor analysis reasonably fits well; the model chi-square $\left(\chi^{2}\right)$ value was 515.18 with $194 \mathrm{df}$, which refers to that the value of $\chi^{2} / \mathrm{df}(2.66)$ is lower than cut-off level 3.0 (Klien, 2010). The Comparative Fit Index (CFI) and the Tucker-Lewis Index (TLI) support the conclusion that the model including six theoretical constructs fits $(\mathrm{CFI}=0.939$ and $\mathrm{TLI}=0.928)$ acceptably by indicating over cut-off values (see Table 3). The Root Mean Square Error of Approximation (RMSEA) and Standardized Root Mean Square Residual (SRMR) were also calculated to evaluate the model fit (RMSEA $=0.075$ and SRMR =0.046). While the values are slightly higher than the recommended levels $(<0.05)$, Hu and Bentler (1999) suggested that values of RMSEA below 0.10 and SRMR as high as .07 are deemed acceptable. Thus, it can be concluded that the results of the model indexes show the reasonable values as well. 


\section{Structural model}

Given confirming the measurement model, the structural model was assessed to examine the hypothesized relationships among the latent factors. SEM using Maximum Likelihood estimation was undertaken using M-Plus. The goodness-of-fit results show that 2.72 of $\chi^{2} / \mathrm{df}$ (p $<.001)$, CFI (0.936), TLI (0.925), RMSEA (0.076) and SRMR (0.05), which suggests that the estimated model built on the covariance metrics is reasonably acceptable (see Figure 2).

To be more specific, the path relationships are statistically significant except for the relationship between perceived cost and purchasing intention $(\beta=0.06, p>0.05)$. As this study proposed, self-efficacy positively affects perceived behavioural control $\left(\beta=.77, p<.001, R^{2}\right.$ $=0.59)$ and negatively influences anxiety $\left(\beta=-0.62, p<0.001, R^{2}=0.38\right)$. With regard to the direct antecedents of intention to book hotels using smartphones, perceived benefit ( $\beta=0.33$, $\mathrm{p}<0.001)$ and perceived behavioural control $(\beta=0.45, \mathrm{p}<0.001)$ positively as well as anxiety $(\beta=-0.25, p<0.001)$ negatively affects the endogenous variable (purchasing intention), which accounts for $70 \%$ of variance explained $\left(\mathrm{R}^{2}=0.70\right)$ (see Figure 2$)$.

[Insert Figure 2 here]

The indirect effect of self-efficacy on purchasing intention was also estimated by concerning Sobel test. Table 4 presents that self-efficacy has statistically indirect influence via both perceived behavioural control $(\beta=0.31, \mathrm{p}<0.001)$ and anxiety $(\beta=0.14, \mathrm{p}<0.001)$ on intention to book a hotel room using smartphones.

[Insert Table 4 here] 
Then, this study calculated the post-hoc statistical power to test the insignificant relationship between perceived cost and behavioural intention reflecting Hypothesis 3 (Cohen, 1988). The observed statistical power indicates 0.99 given the probability of the relationship, .01, which suggests that the chance of a Type II error occurring for the specific hypothesized relationship is very restricted.

\section{Common method bias}

Podsakoff et al., (2003) suggests that there would be potential of error embedded in the studies when the data for the exogenous and endogenous variables are obtained from same respondents in the same measurement context utilizing the survey method. Thus, this research conducted three steps to assess the potential errors in the model: correlation analysis, Harman's single factor and marker (latent) variable approach. Shown at Table 3, the correlation matrix presents that all of values are below 0.90 . Then, the result of Harmon's single factor test indicated that the unrotated principal component analysis shows $46.02 \%$ of the total variance, which is below cut-off value, 50\%. Last, employing a latent variable approach, the results indicate that the inclusion of a marker factor does not significantly improve the general model fit compared to the revised measurement model without the method factor (see Table 5). Therefore, the results of three different estimations to test common method bias reveal limited common method errors in the analytical model.

[Insert Table 5 here] 


\section{Discussion}

In recognising the importance of smartphones to the hospitality business, previous researchers have mainly discussed consumers' adoption of smartphones in relation to TAM theory, emphasising perceived usefulness and ease of use as well as the roles of technology in the information search stage (Kim et al., 2008; Oh et al., 2009). However, efforts to identify factors that affect transaction behaviours using mobiles are limited, despite the large potential for expanding the future market in hospitality industries. Accordingly, this study adopted the concept of consumer values that suggests a trade-off between perceived benefits and sacrifices (i.e. costs and anxiety) and TPB, which proposes the importance of PBC and self-efficacy factors. As a result, this paper identifies the roles of perceived benefit, PBC and self-efficacy as direct or indirect motivators, whereas anxiety serves as an inhibitor to behavioural intentions to use smartphones for booking hotel accommodation.

More specifically, perceived behavioural control has a positive influence on mobile hotel booking behaviour. This finding is consistent with the results of previous studies (e.g. Hansen, 2008; Kidwell and Jewell, 2010), which argued that the behavioural intention increases when consumers perceive a particular task to be easy to perform. In other words, online consumers are more likely to use smartphones for purchasing products when they can recognise that doing so via new technology is a simple, uncomplicated transaction. This study also identified that perceived benefit is one of the main motivators for inducing reservations via smartphones (e.g. Parra-López et al., 2011). In other words, online travellers who recognise the benefits of using smartphones from past experiences or knowledge tend to have greater intention to use mobile devices for booking hospitality products.

While several previous studies stated that perceived costs are negatively associated with behavioural intentions in e-commerce (e.g. Maity, 2010; Parra-López et al., 2011), the current study relating to the mobile purchasing aspect shows an insignificant relationship. It is apparent 
that as the use of smartphones in daily life increases, people may adjust the marginal levels of effort and time required to use them, and express less concern over the potential risk in using a mobile. Consistently, the respondents in this current study showed average values of perceived costs below the median (mean $=2.60 ; \mathrm{SD}=0.98$ ) (see Table 3 ). Additionally, Melenhorst et al. (2006) suggested evidence of benefit-driven selectivity in the selection process of using a technology. People critically encourage and discourage activities based upon the merits of choice. In other words, online consumers perceive that any investment of time/effort in the adoption of innovative technology is wasted when it does not yield a benefit, but is worth spending on something valuable.

A negative correlation between anxiety and intention to secure reservations via mobile devices appeared in this study. This finding is consistent with previous studies, such as those by Compeau et al. (1999), Beaudry and Pinsonneault (2010), and Yang and Forney (2013). In other words, consumers who purchase travel products using smartphones (advanced ICT) may incur anxiety from potentially uncertain outcomes, an unsuccessful transaction and individual mistakes during the transaction, which may create reluctance to purchase products via smartphones.

Finally, self-efficacy directly affects perceived benefit and anxiety and indirectly influences intention to reserve hotel accommodation using a mobile device (Pavlou and Fygenson, 2006; Yang, 2012). This implies that the level of individuals' confidence in their ability to complete a task with a positive outcome influences perceptions for estimating behavioural control, and negatively influences anxiety. Consumers who have a high level of self-efficacy use smartphones with relative ease and, in turn, that characteristic improves their confidence in purchasing hospitality products via smartphones. On the other hand, those who feel less confident in their ability to accomplish an online reservation have a relatively higher 
level of discomfort, and are therefore less likely to use a smartphone for that purpose (Fagan et al., 2003).

\section{Theoretical implications}

This research provides a theoretical contribution to the hospitality literature by identifying the factors that have positive and negative influences on intentions to make hotel reservations via smartphones. Most previous studies have applied TAM theories developed from the organisational context to assess the adoption of smartphones on hospitality activities, which implicitly assumes that behaviour is volitional. However, smartphone users are confronted by several new constraints pertaining to the use of new technology, such as uncertainty of outcomes from use, lack of control, etc. These issues induce a need to assess elements more relevant to consumer behaviour instead of technological (systematic) aspects. In addition, the TAM theory emphasises two belief factors, usefulness and ease of use, which imply limited explanatory and predictive power, triviality and a lack of practical value (Bagozi, 2007). More importantly, while there are numerous studies that have explained the information search behaviours using the advanced technology (Wang et al., 2012), the research that focuses on transactional behaviours on smartphones is largely limited. Accordingly, this study sheds light on consumers' use of smartphones to book a hotel in regard to the concept of consumer values and the TPB model. As a result, this research finds significant motivators and obstacles in relation to mobile hotel booking behaviours.

\section{Practical implications}

The findings of this research provide hotel marketers with important practical suggestions for motivating consumers reserving accommodation via smartphones. Marketers should simplify the process to improve mobile purchasing confidence through transactions that allow 
individuals to control systems personally. For example, the development of a concise mobile web page or application with clear navigation would enhance the perceived behavioural control that forms consumers' experiences regarding the purchasing process. Moreover, marketers need to educate current and potential online consumers to become aware of competitive benefits (e.g. optimised recommendations and last-minute offers from location-based systems) by providing advertisements/promotions. Offering a showcase to exhibit the positive outcomes would be also important for allowing online consumers to recognise the potential benefits in using the smartphones for a hotel reservation. To enhance self-efficacy, demonstrations via web video would be helpful in order for users to become more familiar with mobile systems. Furthermore, creating alliances with credit card companies could be a valuable solution for relieving anxiety when consumers have to provide personal or banking information. For instance, such a collaboration may facilitate the transaction process by sharing user information and reducing risk with a strong security policy/system on the part of the credit card company.

\section{Limitations and future research}

A number of suggestions for future research are apparent in connection with the limitations in this study. First, building on the current study's estimation of behavioural intention for mobile purchasing, future research should investigate actual purchasing behaviour. Accordingly, longitudinal research should estimate and track the cause of motivators and inhibitors to actual mobile purchasing behaviours. Second, a model considering more contextually specific variables (e.g. mobile trust) as well as diverse geographic destinations is a recommendation for future research (Gregori et al., 2014). With the advantages of a mixed method approach, it is suggested that studies that combine quantitative and qualitative approaches have more insightful findings. Finally, while this research focuses on smartphone services as a whole, it 
is suggested that scholars should seek to understand the difference in online consumer behaviours between smartphone applications and web browsers. 


\section{References}

Ajzen, I. (1991), “The theory of planned behaviour", Organizational Behavior and Human Decision Processes, Vol. 50 No. 2, pp.179-211.

Akturan, U. and Tezcan, N. (2012), "Mobile banking adoption of the youth market: Perceptions and intentions", Marketing Intelligence and Planning, Vol. 30 No. 4, pp. 444-459.

Al-Swidi, A., Behjati, K.S. and Shahzad, A. (2012), "Antecedents of online purchasing intention among MBA students: The case of University Utara Malaysia using the partial least squares approach", International Journal of Business and Management, Vol. 7 No. 15, pp. 35-49.

Amaro, S. and Duarte, P. (2015), “An integrative model of consumers' intentions to purchase travel online", Tourism Management, Vol. 46, pp. 64-79.

Bagozi, R.P. (2007), "The legacy of the technology acceptance model and a proposal for a paradigm shift", Journal of the Association for Information Systems, Vol. 8 No. 4, pp. 244-254.

Balasubramanian, S., Peterson, R.A. and Jarvenpaa, S.L. (2002), "Exploring the implications of M-Commerce for Markets and Marketing", Journal of the Academy of Marketing Science, Vol. 30 No. 4, pp. 348-361.

Bandura, A. (1994). Self-efficacy: The Exercise of Control. New York: W.H. Freeman.

Beaudry, A. and Pinsonneault, A. (2010), "The other side of acceptance: Studying the direct and indirect effects of emotions on information technology use", $M I S$ Quarterly, Vol. 34 No. 4, pp. 689-710.

Bouwman, H., Carlsson, C., Molina-Castillo, F.J. and Walden, P. (2007), "Barriers and drivers in the adoption of current and future mobile services in Finland", Telematics and Informatics, Vol. 24, pp. 145-160.

Buhalis, D. and Law, R. (2008), "Progress in information technology and tourism management: 20 years on and 10 years after the Internet-The State of eTourism research", Tourism Management, Vol. 29 No. 4, pp. 609-623.

Chan, S.S., Fang, X., Brzezinski, J.R., Zhou, Y., Xu, S. and Lam, J. (2002), "Usability for mobile commerce across multiple form factors", Journal of Electronic Commerce Research, Vol. 3 No. 3, pp. 187-199.

Cohen, J. (1988), Statistical Power Analysis for the Behavioral Sciences (2nd Edition). Hillsdale, NJ: Lawrence Earlbaum Associates.

Compeau, D. and Higgins, C.A. (1995), "Computer self-efficacy: Development of a measure and initial test”, MIS Quarterly, Vol. 19 No. 2, pp. 189-211.

Compeau, D.R., Higgins, C.A. and Huff, S. (1999), "Social cognitive theory and 
individual reactions to computing technology: A longitudinal study", MIS Quarterly, Vol. 23 No. 2, pp. 145-158.

Escobar-Rodriguez, T. and Carvajal-Trujillo, E. (2014), "Online purchasing tickets for low cost carriers: An application of the unified theory of acceptance and use of technology (UTAUT) model”, Tourism Management, Vol. 43 No. 1, pp. 70-88.

Expedia Media Solutions (2015a), "The rise of mobile adoption: Sentiment and opportunity for British traveller"; Expedia Media Solutions, available at: http://advertising.expedia.com/insights/research/. (accessed 20 August 2015).

Expedia Media Solutions (2015b), "Travel decisions in a multiscreen world"; Expedia Media Solutions, available at: http://advertising.expedia.com/insights/research/. (accessed 20 August 2015).

Fagan, M., Neill, H.S. and Wooldridge, B.R. (2003), "An empirical investigation into the relationship between computer self-efficacy, anxiety, experience, support and usage", Journal of Computer Information Systems, Vol. 44 No. 2, pp. 95-104.

Gefen, D., Karahanna, E. and Straub, D.W. (2003), "Trust and TAM in online shopping: An integrated model”, MIS Quarterly, Vol. 27 No. 1, pp. 51-90.

Gregori, N., Daniele, R. and Altinay, L. (2014), “Affiliate marketing in tourism: Determinants of consumers' trust”, Journal of Travel Research, Vol. 53 No. 2, pp. 196-120.

Hansen, T. (2008), "Consumer values, the theory of planned behaviour and online grocery Shopping”, International Journal of Consumer Studies, Vol. 32 No. 2, pp. 128-137.

Hauser, J.R. and Wernerfelt, B. (1990), "An evaluation cost model of consideration sets", Journal of Consumer Research, Vol. 16 No. 4, pp. 393-408.

Hu, L. and Bentler, P.M. (1999), "Cutoff criteria for fit indexes in covariance structure analysis: Conventional criteria versus new alternatives", Structural Equation Modeling, Vol. 6,pp. 1-55.

Huang, Y-C., Backman, S.J., Backman, K.F. and Moore, D. (2013), "Exploring user acceptance of 3D virtual worlds in travel and tourism marketing", Tourism Management, Vol. 36, pp. 490-501.

HeBS digital (2012), "2013 Hotel Mobile Technology Trends"; HeBS digital, available at: http://www.hebsdigital.com/blog/2013-hotel-mobile-technology-trends/ (accessed 01 December 2013).

Iconaru, C. (2013), "The moderating role of perceived self-efficacy in the context of online buying adoption", Broad Research in Accounting, Negotiation, and Distribution, Vol. 4 No. 1, pp. 20-29.

Kidwell, B. and Jewell, R.D. (2010), “The motivational impact of perceived control on 
behavioral intentions", Journal of Applied Social Psychology, Vol. 40 No. 9, pp. 24072433.

Kim, D.J., Donald, L.F. and Rao, H.R. (2008), “A trust-based consumer decision-making model in electronic commerce: The role of trust, perceived risk, and their antecedents", Decision Support Systems, Vol. 44 No. 2, pp. 544-564.

Kim, D-Y., Park. J. and Morrison, A. (2008), "A model of traveller acceptance of mobile Technology”, International Journal of Tourism Research, Vol. 10 No. 5, pp. 393407.

Kim, H-W., Chan, H.C. and Gupta, S. (2007), "Value-based adoption of mobile Internet: An empirical investigation", Decision Support Systems, Vol. 43, pp. $111-126$.

Kim, K.K., Shin, H.K. and Kim, B. (2011), "The role of psychological traits and social factors in using new mobile communication services", Electronic Commerce Research and Applications, Vol. 10 No. 4, pp. 408-417.

Kline, R.B. (2011). Principles and Practice of Structural Equation Modeling. Third Edition, New York: Guilford.

Kotler, P. and Armstrong, G. (2003), Principles of Marketing. Prentice Hall, 10th edition,

Kramer, R., Modsching, M., Hagen, K. and Gretzel. U. (2007), "Behavioural impacts of mobile tour guides", In proceeding Information and Communication Technologies in Tourism 2007, pp. 109-118.

Krum, C. (2010), Mobile Marketing. Indianapolis: Pearson Education.

Kuisma, T., Laukkanen, T. and Hiltunen, M. (2007), "Mapping the reasons for resistance to internet banking: A means-end approach", International Journal of Information Management, Vol. 27 No. 2, pp. 75-85.

Lee, Y., Kim, J., Lee, I. and Kim, H. (2002), “A cross-cultural study on the value structure of mobile internet usage: Comparison between Korea and Japan", Journal of Electronic Commerce Research, Vol. 3 No. 4, pp. 227-239.

Liebermann, Y. and Stashevsky, S. (2009), "Determinants of online shopping: Examination of an early-stage online market", Canadian Journal of Administrative Sciences, Vol. 26 No. 4, pp. 316-331.

Lu, H-P. and Su, P.Y-J. (2009), "Factors affecting purchase intention on mobile shopping web sites", Internet Research, Vol. 19 No. 4, pp.442 - 458

Maity, M. (2010), "Critical factors of consumer decision-making on M-commerce: A qualitative study in the United States", International Journal of Mobile Marketing, Vol. 5 No. 2, pp. 87-101.

Melenhorst, A-S., Rogers, W.A. and Bouwhuis, D.G. (2006), “Older adults’ motivated 
choice for technological innovation: Evidence for benefit-driven selectivity", Psychology and Aging, Vol. 21 No. 1, pp. 190-195.

Mintel. (2014a), Holiday planning and booking process - UK. Mintel Report, November.

Mintel. (2014b), Hotels - UK. Mintel Report, October.

Morosan, C. (2014), "Toward an integrated model of adoption of mobile phones for purchasing ancillary services in air travel", International Journal of Contemporary Hospitality Management, Vol. 26 No. 2, pp.246 - 271.

Nunnally, J.C. and Bernstein, I.H. (1994), Psychometric Theory. 3rd edition. New York: McGraw-Hill.

Oh, S., Lehto, X.Y. and Park, J. (2009), "Travelers' intent to use mobile technologies as a function of effort and performance expectancy", Journal of Hospitality Marketing and Management, Vol. 18 No. 8, pp. 765-781.

Okazaki, S. and Hirose, M. (2009), "Does gender affect media choice in travel information search? On the use of mobile Internet", Tourism Management, Vol. 30, pp. 794-804.

Park, C-H. and Kim, Y-G. (2006), "The effect of information satisfaction and relational benefit on consumers' online shopping site commitments", Journal of Electronic Commerce in Organizations, Vol. 4 No. 1, pp. 70-90.

Park, S. and Wang, D. (2013), "A model of travel information search using smartphones: Temporal dimension approach", In proceedings of $72^{\text {nd }}$ TOSOK International Tourism Conference, Seoul, South Korea.

Parra-López, E., Bulchand-Gidumal, J., Gutiérrez-Taño, D. and Díaz-Armas, R. (2011), “ Intentions to use social media in organizing and taking vacation trips", Computers in Human Behavior, Vol. 27 No. 2, pp. 640-654.

Patterson, P.G. and Smith, T. (2001), "Relationship benefits in service industries: A replication in a Southeast Asian context", Journal of Services Marketing, Vol. 15 No. 6, pp. 425-443.

Pavlou, P.A. and Fygenson, M. (2006), "Understanding and predicting electronic commerce adoption: An extension of the theory of planned behaviour", MIS quarterly, Vol. 30 No. 1, pp. 115-143.

Pavlou, P., Liang, H. and Xue, Y. (2007), "Understanding and mitigating uncertainty in online exchange relationships: A principal-agent perspective”, MIS Quarterly, Vol. 31 No. 1, pp. 105-136.

Rasinger, J., Fuchs, M., Beer, T. and Hopken, W. (2009), "Building a mobile tourist guide based on tourists' on-site information needs", Tourism Analysis, Vol. 14 No. 4, pp. 483502. 
Podsakoff, P.M., MacKenzie, S.B., Lee, J.Y. and Podsakoff, N.P. (2003), "Common method biases in behavioural research: A critical review of the literature and recommended remedies" Journal of Applied Psychology, Vol. 88, pp. 879-903.

Swartz, N. (2001), "Hot and cold M-commerce opportunities m-commerce will heat up in situations where applications are convenient, low cost and highly addictive", Wireless Review, Vol. 18, pp. 32-43.

Taylor, S. and Todd, P. A. (1995), “Assessing IT usage: The role of prior experience”, MIS Quarterly, Vol. 19 No. 4, pp. 561-570.

Tsai, Y., Wang, C., and Lu, M., (2011), "Using technology acceptance model to analyze ease of use of a mobile communication system", Social Behavior \& Personality: An International Journal, Vol. 39 No. 1, pp. 65-69.

Thatcher, J.B. and Perrewe, P.L. (2002), "An empirical examination of individual traits as antecedents to computer anxiety and computer self-efficacy", MIS Quarterly, Vol. 26 No. 4, pp. 381-396.

Tussyadiah, I.P. and Zach, F. (2012), "The role of geo-based technology in place Experiences", Annals of Tourism Research, Vol. 39 No. 2, pp. 780-800.

Wang, D., Park, S. and Fesenmaier, D.R. (2012), "The role of smartphones in mediating the touristic experience", Journal of Travel Research, Vol. 51 No. 4, pp. 371-387.

Wang, D., Xiang, Z. and Fesenmaier, D.R. (2014), "Adapting to the mobile world: A model of smartphone use”, Annals of Tourism Research, Vol. 48, pp. 11-26.

Wang, H-Y. and Wang, S-H. (2010), "Predicting mobile hotel reservation adoption: Insight from a perceived value standpoint", International Journal of Hospitality Management, Vol. 29, pp. 598-608.

Wolfinbarger, M. and Gilly, M. C. (2001), "Shopping online for freedom, control, and fun", California Management Review, Vol. 43 No. 2, pp. 34-55.

Wu, E.H.C., Law, R. and Jiang, B. (2013), "Predicting browsers and purchasers of hotel websites: A weight-of-evidence grouping approach", Cornell Hospitality Quarterly, Vol. 54 No. 1, pp. 38-48.

Yang, K. (2012), "Consumer technology traits in determining mobile shopping adoption: An application of the extended theory of planned behaviour", Journal of Retailing and Consumer Services, Vol. 19 No. 5, pp. 484-491.

Yang, K. and Forney, J.C. (2013), "The moderating role of consumer technology anxiety in mobile Shopping", Journal of Electronic Commerce Research, Vol. 14 No. 4, pp. 337-347. 


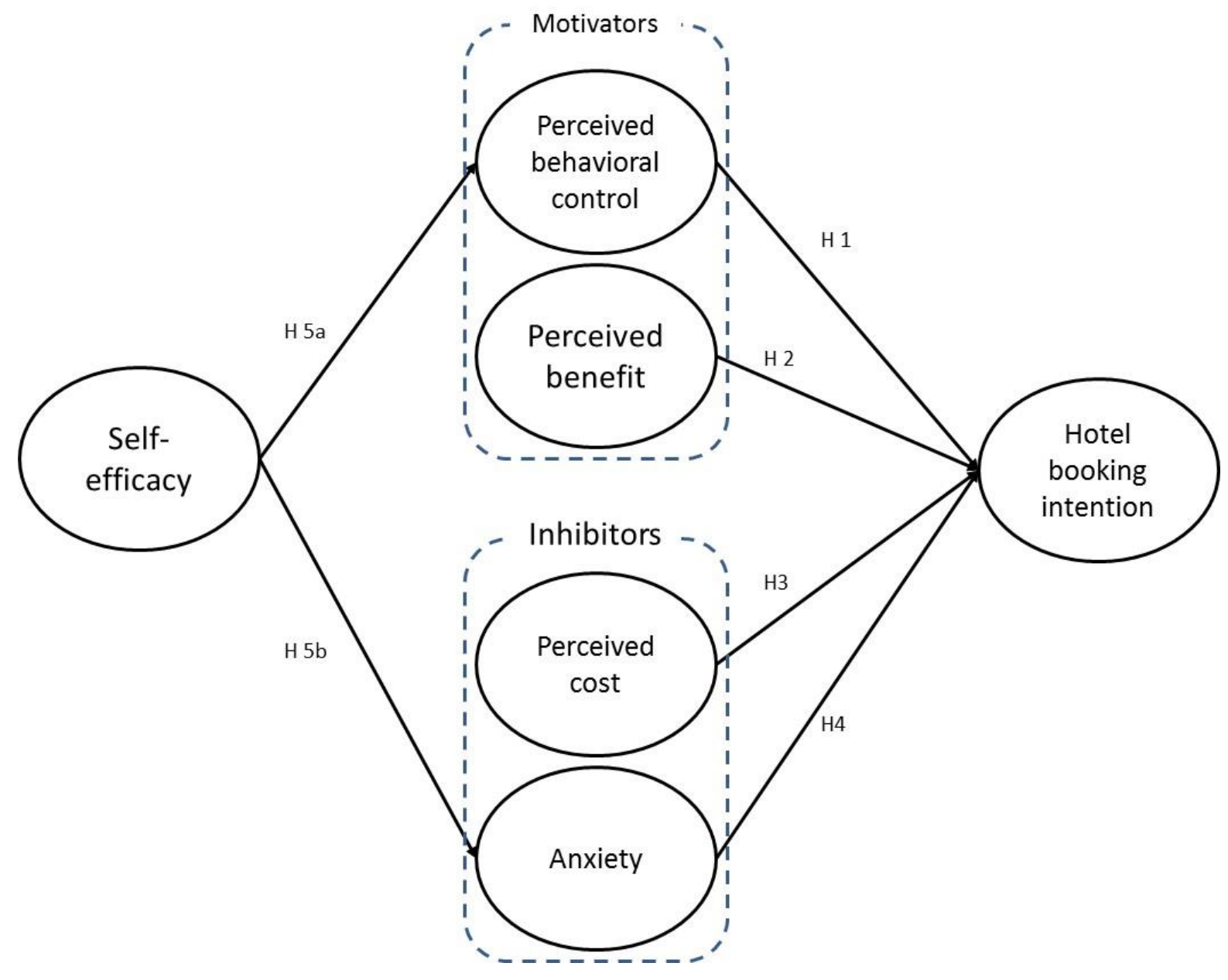

Figure 1.

The proposed model 


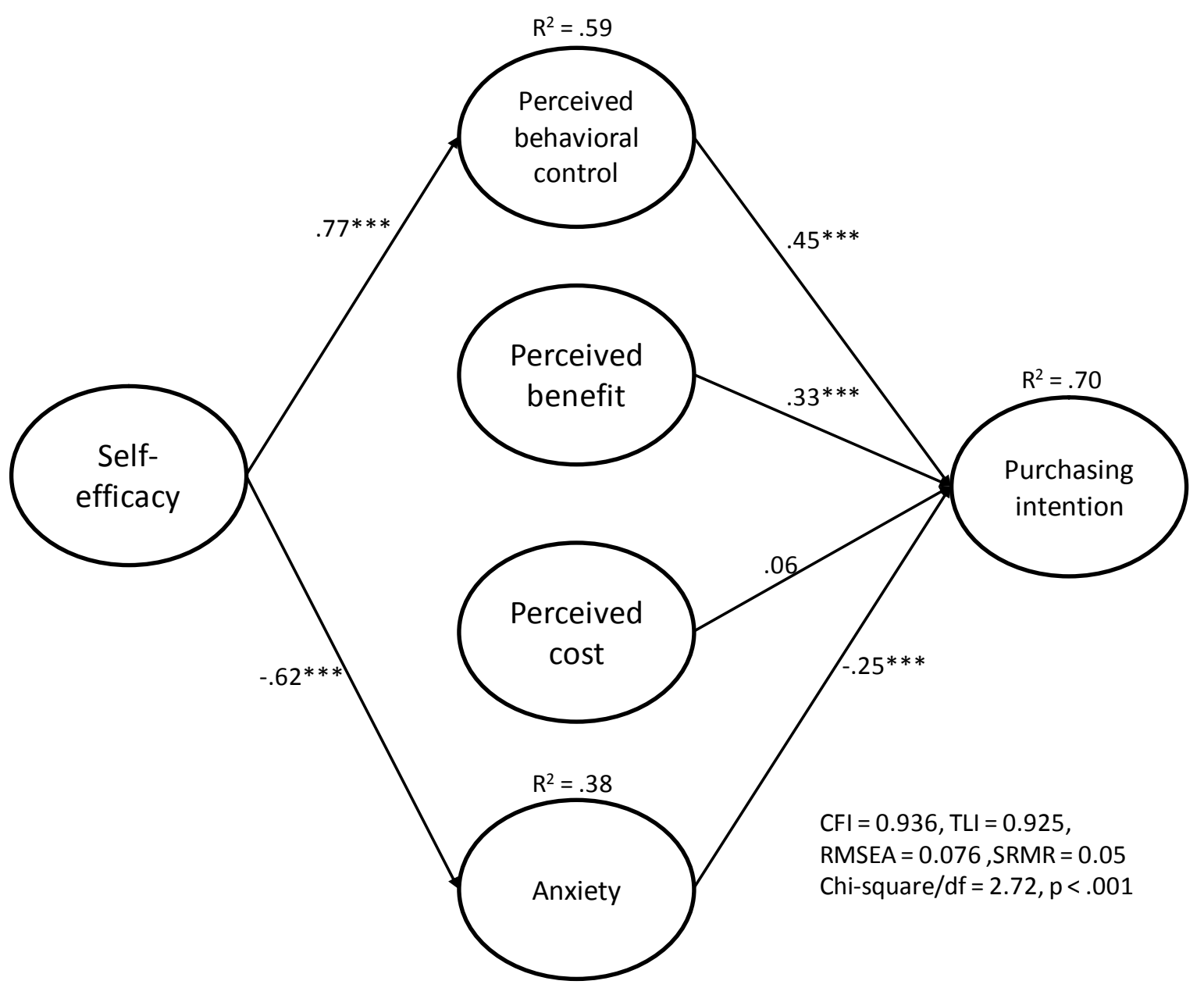

Figure 2.

The structural model 
Table I.

The results of confirmatory factor analysis.

\begin{tabular}{|c|c|c|c|c|}
\hline & $\begin{array}{c}\text { Factor } \\
\text { loadings }\end{array}$ & S.E. & t-values & $\begin{array}{l}\text { Construct } \\
\text { reliability }\end{array}$ \\
\hline Perceived Behavioural Control & & & & 0.93 \\
\hline $\begin{array}{l}\text { PBC_1: I have an Internet-enabled mobile } \\
\text { phone (or smartphone) to access the hotel } \\
\text { booking sites }\end{array}$ & 0.70 & 0.03 & $21.28 * * *$ & \\
\hline $\begin{array}{l}\text { PBC_3: Easy for me to use the system when } \\
\text { booking a hotel via mobile devices. }\end{array}$ & 0.92 & 0.02 & $61.98 * * *$ & \\
\hline $\begin{array}{l}\text { PBC_4: I have the knowledge necessary for } \\
\text { mobile hotel booking. }\end{array}$ & 0.89 & 0.02 & $53.32 * * *$ & \\
\hline Perceived Benefit & & & & 0.92 \\
\hline $\begin{array}{l}\text { PB_1: Keeping up to date with knowledge about } \\
\text { the hotels of interest. }\end{array}$ & 0.80 & 0.02 & $33.40 * * *$ & \\
\hline $\begin{array}{l}\text { PB_2: Permitting to save costs and get the most } \\
\text { from the resources invested in the trip. }\end{array}$ & 0.80 & 0.02 & $32.88 * * *$ & \\
\hline $\begin{array}{l}\text { PB_3: Giving the possibility to provide and to } \\
\text { receive information about hotels of interest }\end{array}$ & 0.81 & 0.02 & $34.86 * * *$ & \\
\hline PB_4: Both pleasing and fun. & 0.84 & 0.02 & $41.08 * * *$ & \\
\hline PB_5: Be proud of doing so. & 0.72 & 0.03 & $22.92 * * *$ & \\
\hline Perceived Costs & & & & 0.92 \\
\hline $\begin{array}{l}\text { PC_1: The personal effort and time is excessive } \\
\text { and not worthwhile. }\end{array}$ & 0.70 & 0.03 & $20.63 * * *$ & \\
\hline $\begin{array}{l}\text { PC_3: Difficult to spend the time needed to } \\
\text { monitor the mobile hotel websites }\end{array}$ & 0.70 & 0.03 & $20.80 * * *$ & \\
\hline PC_4: High risk of losing my privacy & 0.69 & 0.03 & $20.32 * * *$ & \\
\hline $\begin{array}{l}\text { PC_5: Often involves processes that are too } \\
\text { complicated or bothersome, which makes me } \\
\text { abandon the idea. }\end{array}$ & 0.85 & 0.02 & $39.51 * * *$ & \\
\hline $\begin{array}{l}\text { PC_6: Difficult to know where to book a hotel } \\
\text { via mobile devices. }\end{array}$ & 0.80 & 0.03 & $31.87 * * *$ & \\
\hline Anxiety & & & & 0.92 \\
\hline $\begin{array}{l}\text { Anxiety_1: Feel apprehensive about using } \\
\text { smartphones or mobile devices to book a hotel. }\end{array}$ & 0.88 & 0.02 & $45.54 * * *$ & \\
\hline $\begin{array}{l}\text { Anxiety_2: Hesitate to use smartphones or } \\
\text { mobile devices to book a hotel because I could } \\
\text { make mistakes. }\end{array}$ & 0.79 & 0.03 & $30.43 * * *$ & \\
\hline $\begin{array}{l}\text { Anxiety_3: Using smartphones or mobile } \\
\text { devices to book a hotel is somewhat intimidating } \\
\text { to me. }\end{array}$ & 0.77 & 0.03 & $27.63 * * *$ & \\
\hline Self-Efficacy & & & & 0.96 \\
\hline $\begin{array}{l}\text { SE_1: Feel comfortable booking hotels via } \\
\text { mobile devices on my own. }\end{array}$ & 0.89 & 0.02 & $58.52 * * *$ & \\
\hline SE_2: Easily to book a hotel via mobile devices & 0.88 & 0.02 & $55.40 * * *$ & \\
\hline
\end{tabular}


SE_3: Feel comfortable booking a hotel via mobile devices even if there is no one around me to tell me how to use it.

\section{Behavioural intention}

Intention_1: Intend to book a hotel via smartphones or mobile devices.

Intention_2: Expect my mobile hotel booking to continue in the future.

Intention_3: Intend to make a hotel reservation via smartphones or mobile devices.
$0.93 \quad 0.01 \quad 79.30 * * *$

0.97
$0.87 \quad 0.02 \quad 53.99 * * *$

$0.91 \quad 0.01 \quad 70.75^{* * *}$

$0.97 \quad 0.01 \quad 119.02 * * *$

Note: $* * * p<0.001$ 
Table II.

Latent correlation analysis.

\begin{tabular}{lccccccc}
\hline & Mean (SD) & 1 & 2 & 3 & 4 & 5 & 6 \\
\hline 1. Perceived behavioural control & $3.86(1.07)$ & $\mathbf{0 . 9 0}$ & & & & & \\
2. Self-efficacy & $3.71(1.07)$ & 0.77 & $\mathbf{0 . 9 4}$ & & & \\
3. Perceived benefit & $3.76(0.94)$ & 0.64 & 0.84 & $\mathbf{0 . 8 7}$ & & \\
4. Perceived cost & $2.61(0.98)$ & -0.48 & -0.62 & -0.58 & $\mathbf{0 . 8 3}$ & $\mathbf{0 . 8 8}$ & \\
5. Anxiety & $2.50(1.03)$ & -0.48 & -0.62 & -0.52 & 0.39 & -0.61 & $\mathbf{0 . 9 5}$ \\
6. Behavioural intention & $3.66(1.05)$ & 0.75 & 0.74 & 0.71 & -0.44 &
\end{tabular}

Note: The diagonal elements (in bold) represent the square root of AVE. 
Table III.

Summary of model fit indexes for CFA model.

\begin{tabular}{ccccccc}
\hline Chi-square $\left(\chi^{2}\right)$ & df & $\chi^{2} / \mathrm{df}$ & CFI & TLI & RMSEA & SRMR \\
\hline $515.175^{* * *}$ & 194 & 2.66 & 0.939 & 0.928 & 0.075 & 0.046 \\
\hline Note: $* * * p<0.001$ & & & & & &
\end{tabular}


Table IV.

Estimations of indirect effect

Relationship

Beta S.E. t-values

Self-efficacy $\rightarrow$ Perceived behavioural control $\rightarrow$ Intention

$\begin{array}{lll}0.31 & 0.04 & 7.16^{* * *}\end{array}$

Self-efficacy $\rightarrow$ Anxiety $\rightarrow$ Intention

$\begin{array}{lll}0.14 & 0.04 & 3.55^{* * * *}\end{array}$

Note: $* * * p<0.001$ 
Table V.

Comparison of model fit indices to test the common method bias

\begin{tabular}{cccccc}
\hline & $\chi^{2} / \mathrm{df}$ & CFI & TLI & RMSEA & SRMR \\
\hline Revised model & 2.72 & 0.936 & 0.925 & 0.076 & 0.05 \\
Model with the common method factor & 2.35 & 0.954 & 0.941 & 0.068 & 0.074 \\
\hline
\end{tabular}

